\title{
Van der Waals density functional study of hydrocarbon adsorption and separation in metal-organic frameworks without open metal sites
}

\author{
Timothy Quainoo ${ }^{1, b)}$, Sydney N. Lavan ${ }^{1, b)}$, Zhen-Fei Liu ${ }^{1, a)}$ (6) \\ ${ }^{1}$ Department of Chemistry, Wayne State University, Detroit 48202, USA \\ a) Address all correspondence to this author. e-mail: zfliu@wayne.edu \\ b) These authors contributed equally to this work. \\ Received: 1 July 2021; accepted: 16 August 2021; published online: 18 October 2021
}

Metal-organic frameworks (MOFs) have received significant attention thanks to their promising features in the storage and separation of guest molecules. MOFs without open metal sites are emerging as they are often less susceptible to poisoning compared to those with open metal sites. However, a complete understanding of the binding and gas separation mechanisms in such materials is still missing. In this work, we perform a comparative study of two classes of vanadium-based MOFs without open metal sites: MFM-300-V(III) and MFM-300-V(IV), as well as MIL-47-V(III) and MIL-47-V(IV). We employ first-principles van der Waals density functional theory to find the optimal binding conformations and binding energies of a series of small hydrocarbons within the pores of the aforementioned MOFs. Our study provides insight into the host-guest interactions in such MOFs without open metal sites, especially the role played by the bridging hydroxyl group $\left(\mu_{2}-\mathrm{OH}\right)$. We conclude that the bridging $-\mathrm{OH}$ group acts as a pseudo open metal site in these MOFs.

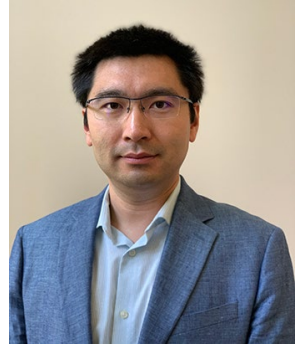

Zhen-Fei Liu
Zhen-Fei Liu received his Ph.D. in chemistry in 2012 from University of California, Irvine, where he worked with Professor Kieron Burke on fundamentals of density functional theory. After that, he worked as a postdoc with Professor Jeffrey B. Neaton at Lawrence Berkeley National Laboratory and University of California, Berkeley, on first-principles calculations of nanostructured materials and charge transport through molecular junctions. In 2018, he joined Wayne State University as an assistant professor in the Department of Chemistry. His group focuses on developments and applications of electronic structure methods for heterogeneous interfaces and functional complex materials. He received the Ralph E. Powe Junior Faculty Enhancement Award from Oak Ridge Associated Universities in 2020, and the NSF CAREER award in 2021.

\section{Introduction}

The separation of light hydrocarbons is a key step in the petroleum refining process. A classic and widely used approach for hydrocarbon separation is fractional distillation [1], which is energy-consuming and can be inefficient for mixtures with very similar boiling points. This consideration led to the development of zeolites [2-4], a type of porous materials in which one of the main driving forces for separation is the difference in adsorption energies between guest molecules and the zeolite [5-8], i.e., the "adsorptive separation." As another type of porous materials, metal-organic frameworks (MOFs) [9-11] have attracted much attention in many areas, such as carbon capture [12-14], catalysis $[15,16]$, precursor in synthesis [17-19], hydrogen storage [20, 21], and gas separation [22-28]. MOFs feature great tunability in pore size and shape $[29,30]$, owing to the rich chemical space that one can explore by combining different linker molecules with different metal centers $[31,32]$, and are thus excellent candidates 
for the adsorptive separation of gas molecules such as small hydrocarbons [33-35].

Most MOFs feature open metal sites, i.e., coordinatively unsaturated metal atoms [36], which tend to interact strongly with $\pi$ orbitals of guest adsorbates. Such a binding preference leads to the separation of $\mathrm{CO}_{2}, \mathrm{C}_{2} \mathrm{H}_{2}$, and $\mathrm{CH}_{4}$ using MOF-74 [37], $\mathrm{O}_{2} / \mathrm{N}_{2}$ separation using different MOFs [38, 39], methanol/acetone separation using M-BTC [40], flue gas separation [41] using MOF-74, among others. In the context of hydrocarbon separation, the same concept explains the separation of olefins from paraffins [42-46]. However, for MOFs with open metal sites, it is reported that there could be a rapid loss in the activity after adsorbates are bound to MOFs, resulting in the poisoning of the metal center and a reduction of the uptake capacities of adsorbates $[41,47]$. To overcome this issue, MOFs without open metal sites have been developed, with prominent examples being NOTT-300-Al [48, 49], MFM-300 series with various metal centers [50-54], and MIL-47-V [55, 56]. However, a fundamental understanding of the binding and gas separation mechanism at the atomistic level in such MOFs, as well as a comparison between different MOFs without open metal sites are still missing. To this end, insights from accurate firstprinciples calculations are needed.

In this work, we employ first-principles density functional theory (DFT) $[58,59]$ with a van der Waals (vdW) functional, vdw-DF-cx [60], to study the binding and separation of four small hydrocarbons-methane $\left(\mathrm{CH}_{4}\right)$, ethane $\left(\mathrm{C}_{2} \mathrm{H}_{6}\right)$, ethene $\left(\mathrm{C}_{2} \mathrm{H}_{4}\right)$, and ethyne $\left(\mathrm{C}_{2} \mathrm{H}_{2}\right)$-in two families of MOFs without open metal sites, namely the MFM-300-V family [61] and the MIL-47-V family [56], both featuring vanadium as the metal center. These MOFs have similar local coordination chemistry near the metal center, and the MFM-300-V family has been experimentally studied for hydrocarbon separation [61]. Within each family, we study two isostructural MOFs with the same topology and connectivity, where the only difference is the oxidation state of vanadium: $\mathrm{V}^{(\mathrm{III})}$ and $\mathrm{V}^{(\mathrm{IV})}$, respectively. Therefore, we perform a comparative study of four MOFs: MFM-300- $\mathrm{V}^{(\mathrm{III}) \text {, }}$ MFM-300-V(IV), MIL-47-V ${ }^{(\mathrm{III})}$, and MIL-47-V(IV). We particularly focus on the local binding geometries of unsaturated hydrocarbons, and use binding energies to explain the experimental trends in hydrocarbon separation. We then attribute the differences between MFM-300-V and MIL-47-V to their different structures. We believe that such a comparative computational study provides insight into a microscopic understanding of gas binding within MOFs without open metal sites and guides future materials design.

Figures 1a-d display all MOF structures studied in this work, where we show one simulation cell for each MOF. MFM$300-\mathrm{V}^{(\mathrm{IV})}\left[\mathrm{MIL}-47-\mathrm{V}^{(\mathrm{IV})}\right]$ is the oxidized counterpart of MFM$300-\mathrm{V}^{(\mathrm{III})}\left[\mathrm{MIL}-47-\mathrm{V}^{(\mathrm{III})}\right]$. Figure 1e highlights the local binding geometry near two neighboring vanadium atoms in both MFM-300- $\mathrm{V}^{(\mathrm{III})}$ and MIL-47- $\mathrm{V}^{(\mathrm{III})}$ structures, where one can see an $-\mathrm{OH}$ group bridging two vanadium atoms, i.e., a $\mu_{2}-\mathrm{OH}$. It also shows that the coordination chemistry in that region is the same for both the MFM-300 family and the MIL-47 family. Each vanadium atom is coordinated with four organic linkers and two bridging - $\mathrm{OH}$ groups, and every adjacent pair of vanadium atoms share three functional groups bridging them: two carboxylate groups in the organic linkers and one $\mu_{2}-\mathrm{OH}$. Figure 1f highlights the local binding geometry near two neighboring vanadium atoms in both MFM-300- $\mathrm{V}^{(\mathrm{IV})}$ and MIL-47- $\mathrm{V}^{(\mathrm{IV})}$, where one can see an oxo group bridging two vanadium atoms (i.e., a $\mu_{2}-\mathrm{O}$ atom) instead of the $\mu_{2}-\mathrm{OH}$, which is the only structural difference between $\mathrm{V}^{(\mathrm{III})}$ and $\mathrm{V}^{(\mathrm{IV})}$ MOFs of the same

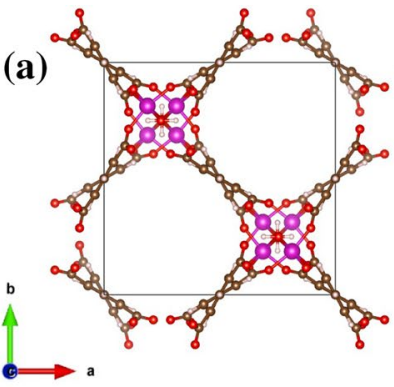

(b)

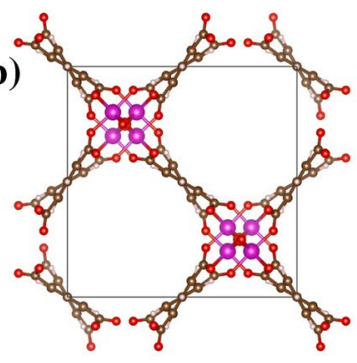

(e)

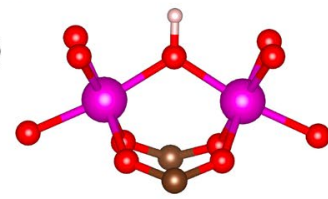

(f)

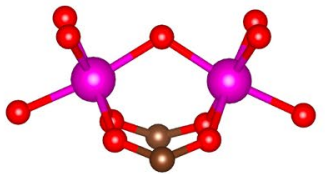

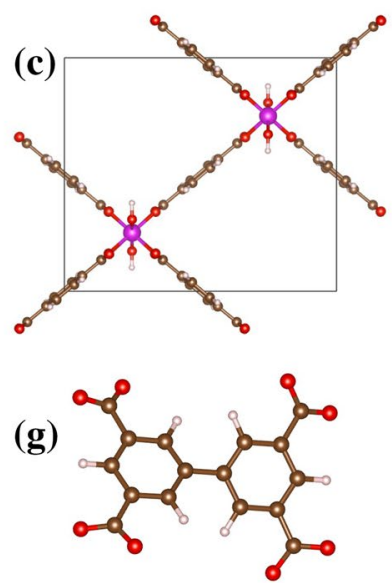

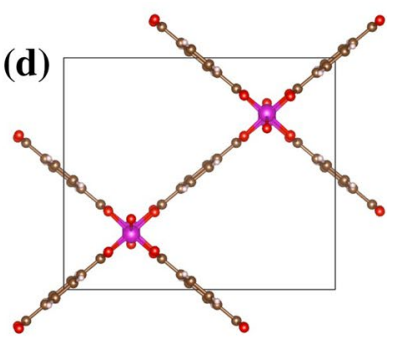

(h)

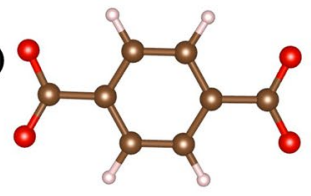

Figure 1: Structures of the four MOFs studied in this work: (a) MFM-300-V(III); (b) MFM-300-V(IV); (c) MIL-47-V(III); and (d) MIL-47-V(IV). Black boxes denote the simulation cells. (e) Zoomed-in view of the bridging hydroxyl group ( $\left.\mu_{2}-\mathrm{OH}\right)$ connecting two $V^{(I I I)}$ atoms in (a) and (c). (f) Zoomed-in view of the bridging oxo group $\left(\mu_{2}-\mathrm{O}\right)$ between two $\mathrm{V}^{(\mathrm{IV})}$ atoms in (b) and (d). (g) the organic linker used in (a) and (b). (h) the organic linker used in (c) and (d). Color Code: C-brown; H-light pink; O-red; V-magenta. All figures in this paper are rendered using VESTA [57]. 
family. Figure $1 \mathrm{~g}$ shows the organic linker present in the MFM$300-\mathrm{V}$ family, the biphenyl-3,3'5,5'-tetracarboxylic acid. MIL$47-\mathrm{V}^{(\mathrm{III})}$ and MIL-47- $\mathrm{V}^{(\mathrm{IV})}$ possess the so-called "wine-rack" motif [62] and feature terephthalic acid as the organic linker, shown in Figure 1h. The structural differences between the MFM-300 and the MIL-47 families as well as between the $\mathrm{V}^{(\mathrm{III})}$ and $\mathrm{V}^{(\mathrm{IV})}$ MOFs of the same family lead to differences in the binding with unsaturated hydrocarbons, as we discuss below.

For each MOF, we consider two binding sites for the guest hydrocarbon molecules. Reference [61] pointed out that there are two distinct binding sites within the MFM-300 family based on neutron powder diffraction (NPD) experiments, which we adopt in this work. Using $\mathrm{C}_{2} \mathrm{H}_{2} @ M F M-300-\mathrm{V}^{(\mathrm{III})}$ as an example (in this paper, we use the “@” sign to denote molecules adsorbed in the pores of a MOF), we show the two binding sites in Fig. 2a, b. At site 1, the molecules are located close to the bridging $-\mathrm{OH}$ groups between two vanadium atoms [c.f. Fig. 1e]. At site 2, the molecules are located close to the organic linkers. Similar binding sites exist for MFM-300- $\mathrm{V}^{(\mathrm{IV})}$. For a direct comparison, we adopt the same two binding sites in our study of MIL-47-V(III) and MIL-47- $\mathrm{V}^{(\mathrm{IV})}$, which are shown in Fig. $2 \mathrm{c}$, d using $\mathrm{C}_{2} \mathrm{H}_{2}$ @MIL-47-V ${ }^{(\mathrm{III})}$ as an example. Since the local coordination chemistry is the same for both MFM-300 and MIL-47 near the vanadium atoms, their differences in binding with guest molecules must arise from the linker, providing insight into structure-property relationship.

The paper is structured as follows: In "Results and discussion" section, we present our results on the binding with each type of hydrocarbons, followed by a discussion on the hydrocarbon separation. We then provide a brief conclusion in "Conclusion" section. The computational parameters are detailed in "Methods".

\section{Results and discussion}

\section{Crystal structure}

Table 1 reports lattice parameters from our geometry relaxations, for the four MOF structures without guest molecules. Our calculations are in good agreement with the literature: Ref. [56] reported that the lattice parameters of MIL-47- $\mathrm{V}^{(\mathrm{III})}$ [MIL$\left.47-\mathrm{V}^{(\mathrm{IV})}\right]$ are $a=16.440 \AA(17.434 \AA), b=13.815 \AA(13.433 \AA)$, and $c=6.886 \AA(6.620 \AA)$. Reference [63] reported that the lattice parameters of MIL-47-V ${ }^{(\mathrm{IV})}$ are $a=16.143 \AA, b=13.939 \AA$, and $c=6.818 \AA$. In Table $S 1$ in the Supplementary Information, we report our calculated lattice parameters for all molecule@MFM$300-\mathrm{V}^{(\mathrm{III})}$ and molecule@MFM-300- $\mathrm{V}^{(\mathrm{IV})}$ structures, which are within $2 \%$ of known experimental values. The adsorption of guest molecules leads to nearly no change in lattice parameters compared to the original MOF. As shown in Fig. 1, MFM-300 has roughly cylindrical pores, with diameters about $11.0 \AA$.
TABLE 1: Calculated crystallographic parameters in Å. In our relaxations, we constrain the symmetry of the MFM-300 family as tetragonal, as determined experimentally [61].

\begin{tabular}{lccc}
\hline \hline & $a$ & $b$ & $c$ \\
\hline MFM-300-V(III) & 14.996 & 14.996 & 12.100 \\
MFM-300-V(IV) & 15.012 & 15.012 & 11.840 \\
MIL-47-V(III) $^{\text {(III) }}$ & 16.277 & 13.951 & 6.642 \\
MIL-47-V $^{\text {(IV) }}$ & 16.135 & 13.788 & 6.823 \\
\hline \hline
\end{tabular}

We constrain the symmetry of the MIL-47 family as orthorhombic, consistent with Ref. [56].
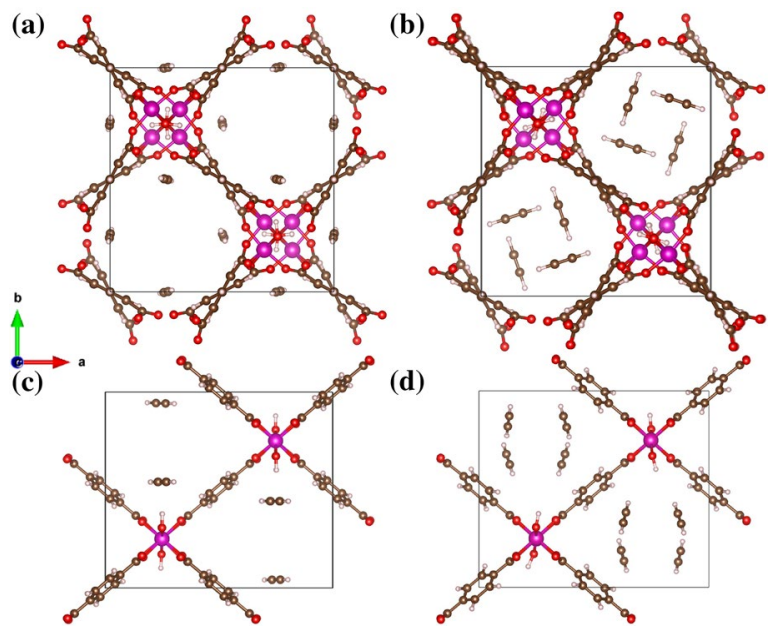

Figure 2: Molecular adsorption sites within the pores of the MOFs. Here, we use the $\mathrm{V}^{(\mathrm{III})}$ MOFs and the $\mathrm{C}_{2} \mathrm{H}_{2}$ molecule as an example to show different adsorption sites. Similar sites for other combinations of MOF structures and guest molecules are shown in Figs. S1-S8 in the Supplementary Information. (a) MFM-300- $\mathrm{V}^{(\text {(III) }}$ binding site 1 ; (b)

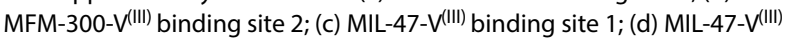
binding site 2 . In (a) and (c), the guest molecules are located close to the bridging - $\mathrm{OH}$ groups. In (b) and (d), the guest molecules are located close to the organic linkers.

MIL-47 has "wine-rack"-shaped pores due to the planar organic linkers, with pore sizes about $16.3 \AA$ along the $a$ direction and $14.0 \AA$ along the $b$ direction.

When guest molecules are adsorbed within the pores of the MOFs, we consider a 1:1 ratio between the number of adsorbates and the number of binding sites to ensure a fair comparison across different binding sites and MOF structures. As shown in Fig. 2, for MFM-300, we consider 8 molecules per unit cell with 4 molecules in each pore, due to the presence of 4 possible binding site 1 positions and another 4 possible binding site 2 positions per pore. Experimentally, this loading corresponds to a gas pressure of 0.3-0.4 bar for the MFM-300 family with $\mathrm{C}_{2} \mathrm{H}_{n}(n=2,4,6)$ [61]. For MIL-47, there are 4 (8) possible binding site 1 (site 2) positions in each unit cell. Furthermore, we consider all molecules within the pores occupying equivalent sites, i.e., all at site 1 or all at site 2 . In reality, both sites could be simultaneously occupied especially at high gas pressure, and 
TABLE 2: The calculated binding energy per molecule in $\mathrm{kJ} / \mathrm{mol}$ between each of the four MOFs and each of the four hydrocarbons.

\begin{tabular}{|c|c|c|c|c|c|c|c|c|}
\hline \multirow{2}{*}{$\begin{array}{l}\text { Hydrocarbon } \\
\text { Binding site }\end{array}$} & \multicolumn{2}{|c|}{$\mathrm{CH}_{4}$} & \multicolumn{2}{|c|}{$\mathrm{C}_{2} \mathrm{H}_{6}$} & \multicolumn{2}{|c|}{$\mathrm{C}_{2} \mathrm{H}_{4}$} & \multicolumn{2}{|c|}{$\mathrm{C}_{2} \mathrm{H}_{2}$} \\
\hline & $\# 1$ & \#2 & $\# 1$ & \#2 & $\# 1$ & \#2 & $\# 1$ & \#2 \\
\hline MFM-300-V(III) & 32.1 & 29.8 & 46.5 & 47.6 & 44.8 & 43.1 & 44.1 & 40.5 \\
\hline MFM-300-V(IV) & 31.1 & 29.9 & 45.1 & 46.5 & 43.0 & 43.1 & 40.6 & 41.4 \\
\hline MIL-47-V(III) & 27.9 & 27.9 & 42.7 & 41.4 & 47.9 & 36.9 & 45.3 & 34.8 \\
\hline MIL-47-V(IV) & 26.3 & 27.4 & 41.1 & 40.1 & 39.0 & 36.6 & 38.5 & 34.0 \\
\hline
\end{tabular}

For each MOF-hydrocarbon pair, we list results for the most stable conformation at each of the two binding sites. the competition between the two sites can be described by a dual-site Langmuir model [64-66]. We comment that what we compute in this work are the limiting cases, which allows us to focus on the local binding mechanism at each site, rather than the kinetics of adsorption/desorption processes.

We show the calculated binding energy per molecule in $\mathrm{kJ} /$ mol in Table 2, for each combination of MOF, hydrocarbon, and binding site. In the following subsections, we discuss the binding with saturated hydrocarbons $\left(\mathrm{CH}_{4}\right.$ and $\left.\mathrm{C}_{2} \mathrm{H}_{6}\right)$, the binding with $\mathrm{C}_{2} \mathrm{H}_{4}$, and the binding with $\mathrm{C}_{2} \mathrm{H}_{2}$, respectively, followed by a discussion of the implications on the hydrocarbon separation process. For each hydrocarbon adsorbate, we compare the performance among the four MOFs and aim to illustrate the structure-property relationship.

\section{Binding with saturated hydrocarbons: $\mathrm{CH}_{4}$ and $\mathrm{C}_{2} \mathrm{H}_{6}$}

We first discuss the case of $\mathrm{CH}_{4}$. Depending on the initial guess structure, our relaxations yield slightly different binding conformations for the molecules within the pores with very similar binding energies. The most stable binding conformations of $\mathrm{CH}_{4}$ at both binding sites of the MFM-300 (MIL-47) family are shown in Fig. S1 in the Supplementary Information, with the binding energies listed in Table 2. We see that for either MFM300 or MIL-47, the two binding sites do not lead to significantly different binding energies, and neither does the oxidation state of the vanadium atom. Such an observation strongly suggests that the binding is purely dispersive without much selectivity in terms of the binding orientation. The MFM-300 in general leads to about $10 \%-15 \%$ higher binding energy than MIL- 47 , perhaps due to the larger molecular weight of the MFM-300 framework, again affirming that the dominating mechanism in the binding between the MOFs and molecules is the dispersion interaction.

The above conclusions apply to $\mathrm{C}_{2} \mathrm{H}_{6}$, another saturated hydrocarbon with higher molecular weight. We show the most stable binding conformations of $\mathrm{C}_{2} \mathrm{H}_{6}$ that we find during our relaxations at both binding sites of the MFM-300 (MIL-47) family in Fig. S3 (Fig. S4) in the Supplementary Information, with the binding energies listed in Table 2. Same as $\mathrm{CH}_{4}$, there is not much preference with respect to the binding site or the oxidation state of the vanadium atom. The values of the binding energies are about 1.5 times of the corresponding values for $\mathrm{CH}_{4}$, and the binding energies in MFM-300 are again about 10\%-15\% higher than those in MIL-47. Based on these facts, we conclude that the directionless dispersion interaction dominates, similar to the case of $\mathrm{CH}_{4}$.

\section{Binding with $\mathrm{C}_{2} \mathrm{H}_{\mathbf{4}}$}

We show the most stable binding conformations of $\mathrm{C}_{2} \mathrm{H}_{4}$ within the pores of MFM-300 (MIL-47) family in Fig. S5 (Fig. S6) in the Supplementary Information, with binding energies listed in Table 2. Here, in contrast to the saturated hydrocarbons, a preference in binding does arise. First, in both MFM-300 and MIL-47, the binding energies are similar at site 2, independent of (a)

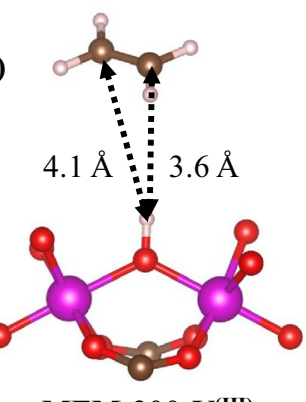

MFM-300-V(III)

(c)

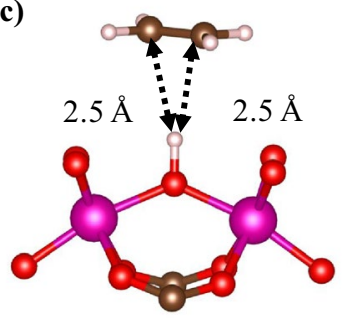

MIL-47-V(III)

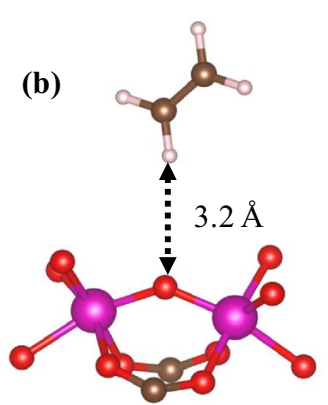

MFM-300-V(IV)

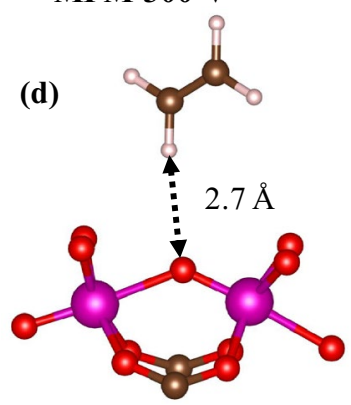

MIL-47-V(IV)

Figure 3: The most stable binding conformation of $\mathrm{C}_{2} \mathrm{H}_{4}$ at binding site 1 in the four MOF structures: (a) MFM-300-V(III); (b) MFM-300-V(IV); (c) MIL-47-V(III); and (d) MIL-47-V(IV). Only one molecule and the closest atoms near the binding site are shown to highlight the local binding environment. For a view of the full simulation cell, see Fig. S5 (Fig. S6) for MFM-300 (MIL-47). 
the oxidation state of vanadium. Second, in both MFM-300 and MIL-47, the binding energy at site 1 of the $\mathrm{V}^{(\mathrm{III})} \mathrm{MOF}$ is larger than both site 2 of the same MOF and site 1 of the $\mathrm{V}^{(\mathrm{IV})} \mathrm{MOF}$, with the difference more pronounced (about $10 \mathrm{~kJ} / \mathrm{mol}$ ) for MIL-47, showing a strong binding preference. Third, for MFM$300-\mathrm{V}^{(\mathrm{IV})}$, the binding energy at site 1 is similar to that at site 2, while for MIL-47- $\mathrm{V}^{\text {(IV) }}$, the binding energy at site 1 is slightly larger than that at site 2 , showing a weak binding preference. We explain all the above observations below with our calculations.

We first note that at site 2, the binding energies for the $\mathrm{V}^{(\mathrm{III})}$ and $\mathrm{V}^{(\mathrm{IV})}$ MOFs are almost identical, for both the MFM300 and the MIL-47 families. This is because the local structures of the $\mathrm{V}^{(\mathrm{III})}$ and $\mathrm{V}^{(\mathrm{IV})}$ MOFs are similar at the linker, where the binding site is located. The situation for site 1 is different. We show in Fig. 3 the local binding geometry near the bridging - $\mathrm{OH}$ or $-\mathrm{O}$ group for the most stable conformation, with pertinent bond distances marked. For MIL-47- $\mathrm{V}^{(\mathrm{III})}$ (Fig. $3 \mathrm{c}$ ), the $\mathrm{C}_{2} \mathrm{H}_{4}$ plane is perpendicular to the bridging - $\mathrm{OH}$ connecting the two vanadium atom in a "side-on" conformation. The distance between the hydrogen atom in the $\mu_{2}$ $\mathrm{OH}$ and the two carbon atoms in $\mathrm{C}_{2} \mathrm{H}_{4}$ is about $2.5 \AA$, which is consistent with the typical bonding distance between an $-\mathrm{OH}$ group and a carbon-carbon double bond [67-69], with the interaction being electrostatic between the electronegative $\pi$ electrons in the carbon-carbon double bond and the electropositive hydrogen in the - $\mathrm{OH}$. The orientation, i.e., carbon $p_{z}$ orbital aligned with the $-\mathrm{OH}$, also supports such a conclusion, making the binding directional.

For MIL-47-V (IV) (Fig. 3d), due to the absence of the hydrogen in the bridging group, the $\mathrm{C}_{2} \mathrm{H}_{4}$ binds to the $\mu_{2}-\mathrm{O}$ using one hydrogen atom in a "head-on" conformation, forming weak $\mathrm{C}-\mathrm{H} \cdots \mathrm{O}$ hydrogen bond, whose binding is also directional. The distance between the hydrogen and the oxygen is $2.7 \AA$, consistent with typical C-H $\cdots$ O bond [70]. During our relaxation, we found other local minima where the

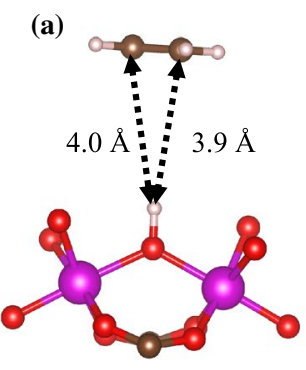

MFM-300-V(III)

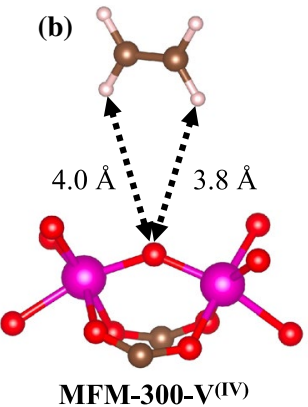

MFM-300-V(IV)
Figure 4: Secondary binding conformation of $\mathrm{C}_{2} \mathrm{H}_{4}$ at (a) site 1 of MFM$300-V^{(I I I)}$ and (b) site 1 of MFM-300-V(IV). These conformations lead to slightly lower binding energies than those shown in Fig. 3. Only one molecule and the closest atoms near the binding site are shown to highlight the local binding environment.
$\mathrm{C}_{2} \mathrm{H}_{4}$ rotates around the $\mathrm{C}-\mathrm{H} \cdots \mathrm{O}$, with similar binding energies $(37-38 \mathrm{~kJ} / \mathrm{mol}$ compared to the most stable $39.0 \mathrm{~kJ} / \mathrm{mol}$ in Fig. 3d). As a comparison, the binding energy with MIL$47-\mathrm{V}^{(\mathrm{III})}$ in Fig. $3 \mathrm{c}$ is $47.9 \mathrm{~kJ} / \mathrm{mol}$, suggesting that the $\mathrm{C}-\mathrm{H} \cdots \mathrm{O}$ hydrogen bonding in $\mathrm{C}_{2} \mathrm{H}_{4} @ \mathrm{MIL}-47-\mathrm{V}^{(\mathrm{IV})}$ is weaker than the $\mathrm{OH}-\pi$ interaction in $\mathrm{C}_{2} \mathrm{H}_{4} @ \mathrm{MIL}-47-\mathrm{V}^{(\mathrm{III})}$.

The situation is quite different for the MFM-300 family. Figure $3 \mathrm{a}$ shows the binding conformation at site 1 of MFM$300-\mathrm{V}^{(\mathrm{III})}$, where $\mathrm{C}_{2} \mathrm{H}_{4}$ does not bind to the bridging $-\mathrm{OH}$ using its $\pi$ electrons as in MIL-47- $\mathrm{V}^{(\mathrm{III})}$ (Fig. 3c), but rather, stay much further away from the MOF, with the distance between the hydrogen atom on the bridging - $\mathrm{OH}$ and the carbon atoms within $\mathrm{C}_{2} \mathrm{H}_{4}$ around $4 \AA$. This length is greater than typical $\mathrm{H}-\pi$ bonding distance and the sum of the $\mathrm{vdW}$ radii of hydrogen and carbon atoms, suggesting that the $\mathrm{H}-\pi$ interaction may not be the dominating binding mechanism. During our relaxations, we have found other local minima, such as the one shown in Fig. 4a that is similar to the "side-on" binding with MIL-47- $\mathrm{V}^{(\mathrm{III})}$. However, even in this conformation, the distance between the hydrogen atom on the bridging $-\mathrm{OH}$ and the carbon atoms within $\mathrm{C}_{2} \mathrm{H}_{4}$ is still about 4 $\AA$, unlike the case of MIL-47- $\mathrm{V}^{(\mathrm{III})}$. Furthermore, it yields an even lower binding energy $(43.6 \mathrm{~kJ} / \mathrm{mol})$ compared to the one reported in Fig. 3a (44.8 kJ/mol). Note that this long distance between the $\mathrm{C}_{2} \mathrm{H}_{4}$ molecule and the MOF does match results from the NPD experiment [61], where the $\mathrm{OH}-\pi$ distance is reported to be $3.74 \AA$.

To understand the nature of the binding of $\mathrm{C}_{2} \mathrm{H}_{4}$ at site 1 of MFM-300-V(III) (Fig. 3a), we plot in Fig. $5 \mathrm{a}$ the change of total charge density upon binding, i.e., $\quad \Delta \rho=\rho$ (molecule@MOF $)-\rho(\mathrm{MOF})-\rho$ (molecule $)$. $\rho$ (molecule@MOF) is the charge density of the composite system, $\rho$ (MOF) is the charge density of the MOF alone, and $\rho$ (molecule) is the charge density of all the molecules. All these quantities are calculated using the same atomic positions and simulation cell of the relaxed molecule@MOF system, so no effects of the geometry change are taken into account. Blue
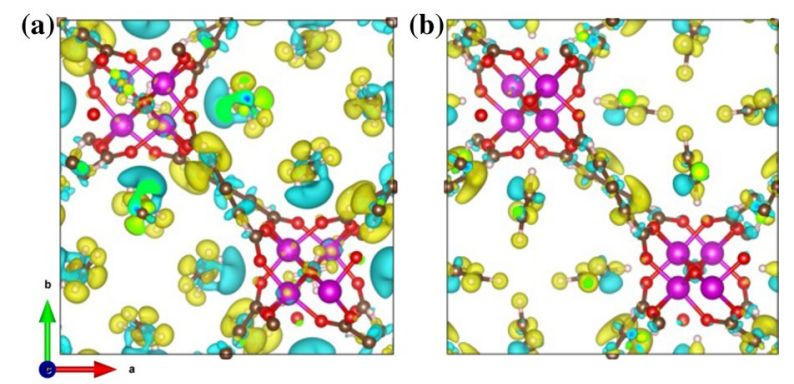

Figure 5: The charge density difference upon binding, $\Delta \rho$, for $\mathrm{C}_{2} \mathrm{H}_{4}$ at (a) site 1 of MFM-300-V(III) and (b) site 1 of MFM-300-V(IV). Blue (yellow) color indicates electron charge accumulation (depletion) upon binding. The same isosurface value is used for both panels. 
(yellow) blobs indicate positive (negative) $\Delta \rho$, i.e., electron charge accumulation (depletion) upon binding. From this figure, one can see that although the molecule is located at site 1 , the bridging $-\mathrm{OH}$ groups only play a marginal role in the binding. Rather, the main binding mechanism is the interaction between the $\mathrm{C}_{2} \mathrm{H}_{4}$ and part of the side chains in the MOFperhaps via a $\pi-\pi$ interaction-similar to the case of site 2 binding. It explains why the binding energy is not significantly larger than that at site 2 for this MOF $(44.8 \mathrm{~kJ} / \mathrm{mol}$ at site 1 and $43.1 \mathrm{~kJ} / \mathrm{mol}$ at site 2 ).

For MFM-300- $\mathrm{V}^{(\mathrm{IV})}$ (Fig. 3b), the binding conformation is similar to that of MIL-47-V(IV) (Fig. 3d), where the $\mathrm{C}_{2} \mathrm{H}_{4}$ binds to the MOF using one hydrogen atom in a "head-on" conformation. However, the distance between the hydrogen atom in $\mathrm{C}_{2} \mathrm{H}_{4}$ and the bridging $-\mathrm{O}$ atom of the MOF is $3.2 \AA$, about $0.5 \AA$ larger than that in MIL- $47-\mathrm{V}^{(\mathrm{IV})}$. This distance of $3.2 \AA$ is also larger than the typical bonding distance in a weak $\mathrm{C}-\mathrm{H} \cdots \mathrm{O}$ hydrogen bond [70-72]. A secondary binding conformation is shown in Fig. 4b, with slightly lower binding energy [ $40.9 \mathrm{~kJ} / \mathrm{mol}$ compared to $43.0 \mathrm{~kJ} / \mathrm{mol}$ in Fig. 3b]. To understand the binding mechanism in Fig. 3b, we again plot $\Delta \rho$, in Fig. 5b. Similar to Fig. $5 \mathrm{a}$, the $\mathrm{C}_{2} \mathrm{H}_{4}$ mainly interacts with the side chains, explaining the fact that the binding energy at site $1(43.0 \mathrm{~kJ} / \mathrm{mol})$ is almost identical to that at site $2(43.1 \mathrm{~kJ} / \mathrm{mol})$.

To conclude this section, the bridging $-\mathrm{OH}$ in MIL-47- $\mathrm{V}^{(\mathrm{III})}$ leads to a strong binding preference with $\mathrm{C}_{2} \mathrm{H}_{4}$ compared to the site 2 of the same MOF ( $11 \mathrm{~kJ} / \mathrm{mol}$ difference) or the site 1 of MIL-47- $\mathrm{V}^{(\mathrm{IV})}(8.9 \mathrm{~kJ} / \mathrm{mol}$ difference), while the bridging $-\mathrm{O}$ atom in MIL-47- $\mathrm{V}^{(\mathrm{IV})}$ leads to a weak binding preference compared to the site 2 of the same MOF $(2.4 \mathrm{~kJ} / \mathrm{mol}$ difference). For the MFM-300 family, the effect of the bridging $-\mathrm{OH}$ or $-\mathrm{O}$ group on the binding preference is much weaker than that in the MIL-47 family. We attribute the difference in the binding properties of these two families of MOFs to their structural difference. From Fig. 1c, one can see that in MIL-47-V $\mathrm{V}^{(\mathrm{III})}$, the bridging $-\mathrm{OH}$ is readily accessible to a guest molecule adsorbed in the pore, due to the wide angle that the linkers form in this "wine-rack" topology. The two carboxylate groups in the linker are in para position of each other (Fig. 1h), making the linker effectively linear. In contrast, in MFM-300-V(III), the carboxylate groups in the linker are in meta position of each other (Fig. 1g). As a result, these carboxylate groups lead to steric hindrances near the bridging - $\mathrm{OH}$ groups (Fig. 1a), preventing a close contact between an adsorbed molecule within the pore and the bridging - $\mathrm{OH}$ group in the MOF.

\section{Binding with $\mathrm{C}_{2} \mathrm{H}_{2}$}

In line with the discussion of the $\mathrm{C}_{2} \mathrm{H}_{4}$ binding, we discuss both the binding energies and binding conformations when $\mathrm{C}_{2} \mathrm{H}_{2}$ is adsorbed in the pores of the four MOFs. The most stable binding
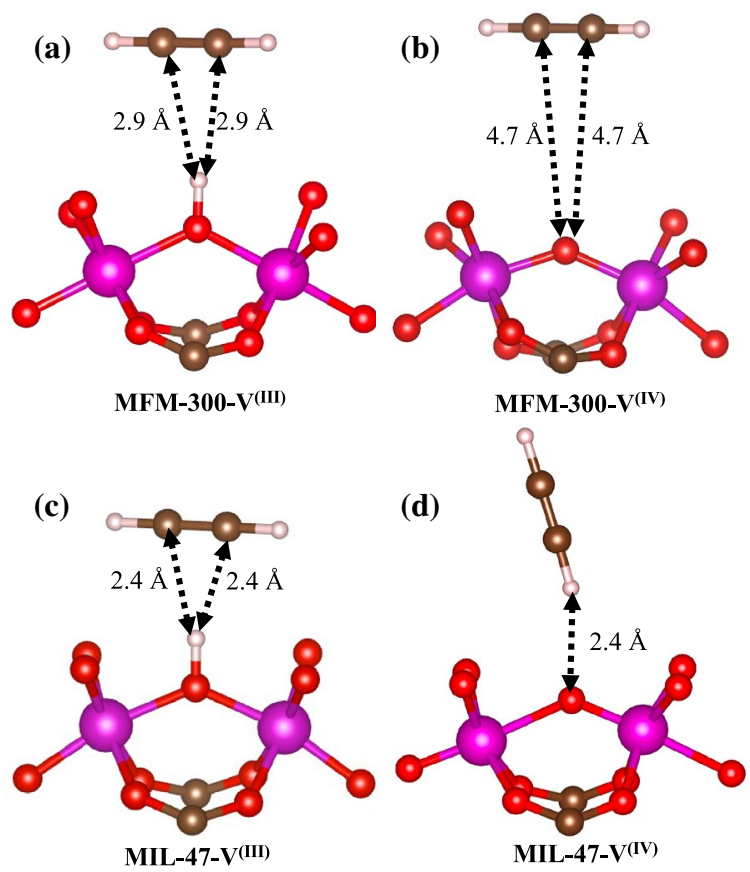

Figure 6: The most stable binding conformation of $\mathrm{C}_{2} \mathrm{H}_{2}$ at binding site 1 in the four MOF structures: (a) MFM-300-V(III); (b) MFM-300-V(IV); (c) MIL-47-V(III); and (d) MIL-47-V(IV). Only one molecule and the closest atoms near the binding site are shown to highlight the local binding environment. For a view of the full simulation cell, see Fig. S7 (Fig. S8) for MFM-300 (MIL-47).

conformations are shown in Fig. S7 (Fig. S8) in the Supplementary Information for the MFM-300 family (MIL-47 family), with binding energies listed in Table 2. The overall trend is similar to that of $\mathrm{C}_{2} \mathrm{H}_{4}$ : First, for the same family, either MFM-300 or MIL-47, the binding energies at site 2 of both the $\mathrm{V}^{(\mathrm{III})} \mathrm{MOF}$ and the $\mathrm{V}^{(\mathrm{IV})}$ MOF are similar. Second, the binding energy at site 1 of the $\mathrm{V}^{(\mathrm{III})}$ MOF is significantly larger than the $\mathrm{V}^{(\mathrm{IV})}$ counterpart, due to the directional binding between the bridging $-\mathrm{OH}$ present in the $\mathrm{V}^{(\mathrm{III})} \mathrm{MOF}$ and the carbon-carbon triple bond. Third, for MFM-300- $\mathrm{V}^{(\mathrm{IV})}$, the binding energy at site 1 is similar to that at site 2 , while for MIL-47- $\mathrm{V}^{(\mathrm{IV})}$, the binding energy at site 1 is slightly larger than that at site 2 . Below we elaborate on the second and third points, particularly focusing on the difference between $\mathrm{C}_{2} \mathrm{H}_{2}$ and $\mathrm{C}_{2} \mathrm{H}_{4}$.

Figure 6 highlights the most stable binding conformations of $\mathrm{C}_{2} \mathrm{H}_{2}$ at binding site 1 in the four MOF structures studied in this work, where we list the distances between the adsorbate molecule and the MOF. In MIL-47-V ${ }^{(\mathrm{III})}$ (Fig. 6c), the $\mathrm{C}_{2} \mathrm{H}_{2}$ and the bridging $-\mathrm{OH}$ are approximately in the same plane, with the $\mathrm{O}-\mathrm{H}$ bond perpendicular to the linear $\mathrm{C}_{2} \mathrm{H}_{2}$ molecule. This conformation suggests that the MOF binds $\mathrm{C}_{2} \mathrm{H}_{2}$ via a $\mathrm{H}-\pi$ interaction, similar to the situation of $\mathrm{C}_{2} \mathrm{H}_{4}$. The distances between the hydrogen atom in the $-\mathrm{OH}$ and the carbon atoms in the triple bond are $2.4 \AA$, slightly shorter than the $\mathrm{H}-\pi$ distance with a carbon-carbon double bond [67]. The binding situation 
(a)
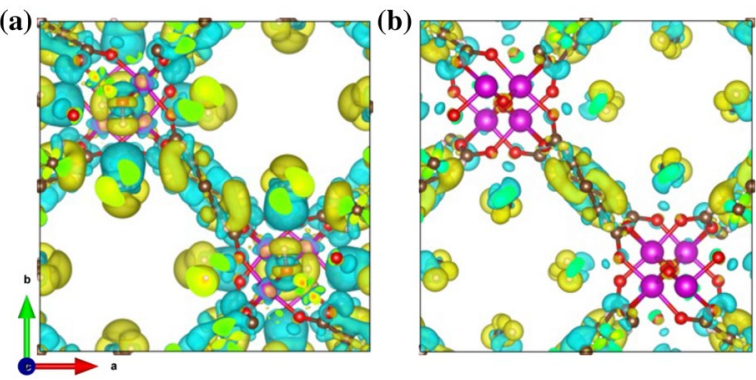

Figure 7: The charge density difference upon binding, $\Delta \rho$, for $\mathrm{C}_{2} \mathrm{H}_{2}$ at (a) site 1 of MFM-300-V(III) and (b) site 1 of MFM-300-V(IV) . Blue (yellow) color indicates electron charge accumulation (depletion) upon binding. The same isosurface value is used for both panels.

for MIL-47- $\mathrm{V}^{(\mathrm{IV})}$ is also similar to that of $\mathrm{C}_{2} \mathrm{H}_{4} @ \mathrm{MIL}-47-\mathrm{V}^{(\mathrm{IV})}$ (Fig. 3d), where the hydrocarbon molecule binds to the MOF via a weak "head-on" C-H $\cdots$ O hydrogen bond. Due to the smaller steric hindrance in the hydrocarbon, $\mathrm{C}_{2} \mathrm{H}_{2}$ binds closer $(2.4 \AA)$ with MIL-47-V ${ }^{(\mathrm{IV})}$ than $\mathrm{C}_{2} \mathrm{H}_{4}(2.7 \AA)$.

For the MFM-300 family, the MFM-300-V $\mathrm{V}^{(\mathrm{III})}$ (Fig. 6a) binds the $\mathrm{C}_{2} \mathrm{H}_{2}$ in a similar way as the MIL-47- $\mathrm{V}^{(\mathrm{III})}$ does, i.e., $-\mathrm{OH}$ interacting with the $\pi$ electrons in the carbon-carbon triple bond. However, the distances between the hydrogen atom and the carbon atoms are about $2.9 \AA$, which is close to the sum of the vdW radii of hydrogen and carbon atoms and hence at the limit of the interaction range. Our result is consistent with Ref. [61], where this distance was determined to be about $3.0 \AA$ based on NPD results. The binding distance is closer than that of $\mathrm{C}_{2} \mathrm{H}_{4} @ M F M-300-\mathrm{V}^{(\mathrm{III})}$ (Fig. 3a), likely due to the smaller steric hindrance of the linear $\mathrm{C}_{2} \mathrm{H}_{2}$ molecule. Besides the attractive interaction between $\mathrm{C}_{2} \mathrm{H}_{2}$ and the bridging $-\mathrm{OH}$ group, the $\Delta \rho$ plot in Fig. 7a shows additional contributions to the binding energy from the interactions between $\mathrm{C}_{2} \mathrm{H}_{2}$ and the linker. Comparing with the case of $\mathrm{C}_{2} \mathrm{H}_{4} @ M I L-47-\mathrm{V}^{(\mathrm{III})}$ (Fig. 5a), one can see small charge accumulation between the $-\mathrm{OH}$ and the $\pi$ electrons in the $\mathrm{C}_{2} \mathrm{H}_{2}$, consistent with the fact that $\mathrm{C}_{2} \mathrm{H}_{2}$ binds closer to the MOF than $\mathrm{C}_{2} \mathrm{H}_{4}$. Moreover, this attractive interaction between the $\pi$ electrons in the $\mathrm{C}_{2} \mathrm{H}_{2}$ and the bridging $-\mathrm{OH}$ group makes the binding energy at site $1(44.1 \mathrm{~kJ} / \mathrm{mol})$ larger than that at site $2(40.5 \mathrm{~kJ} / \mathrm{mol})$.

For MFM-300- $\mathrm{V}^{(\mathrm{IV})}$, our relaxation shows that the most stable structure is a "side-on" conformation (Fig. 6b) with a very long ( $4.7 \AA$ ) distance between the bridging -O atom and the carbon-carbon $\pi$ bond. This is consistent with the NPD results reported in Ref. [61], where this distance is determined to be greater than $4.83 \AA$ A. However, we do not expect such a long distance to give rise to any interaction between the $\mathrm{C}_{2} \mathrm{H}_{2}$ and the bridging - $\mathrm{O}$ atom (let alone the fact that this interaction, if at all possible, must be repulsive because both species are electronegative). To understand the nature of the binding mechanism between $\mathrm{C}_{2} \mathrm{H}_{2}$ and the MOF, we analyze the $\Delta \rho$ plot in Fig. $7 \mathrm{~b}$, which shows that the interaction between $\mathrm{C}_{2} \mathrm{H}_{2}$ and the cluster around the vanadium atoms is negligible. Rather, the contribution to the binding energy is mostly from the interaction between $\mathrm{C}_{2} \mathrm{H}_{2}$ and the linker, even when $\mathrm{C}_{2} \mathrm{H}_{2}$ is located at site 1 . It explains why the binding energy at site $1(40.6 \mathrm{~kJ} / \mathrm{mol})$ is comparable to that at site $2(41.4$ $\mathrm{kJ} / \mathrm{mol}$ ). We note in passing that we have computationally explored another "head-on" conformation (not shown) similar to that of $\mathrm{C}_{2} \mathrm{H}_{2} @ M I L-47-\mathrm{V}^{(\mathrm{IV})}$ (Fig.6d). However, that conformation leads to a much lower binding energy $(36.4 \mathrm{~kJ} / \mathrm{mol})$ than Fig. $6 \mathrm{~b}(40.6 \mathrm{~kJ} / \mathrm{mol})$, likely due to the lack of attractive interactions between the linker and the $\mathrm{C}_{2} \mathrm{H}_{2}$.

Overall, the bridging -OH group in MIL-47-V(III) leads to a strong binding preference compared to the site 2 of the same MOF and the site 1 of MIL-47- $\mathrm{V}^{(\mathrm{IV})}$. Similarly, the bridging $-\mathrm{O}$ group in MIL-47- $\mathrm{V}^{(\mathrm{IV})}$ leads to a weak binding preference compared to the site 2 of the same MOF. However, such preferences are much weaker in the MFM-300 family. There is only a slight preference in binding at site 1 compared to site 2 in MFM-300- $\mathrm{V}^{(\mathrm{III})}$ due to the weak interaction between the bridging $-\mathrm{OH}$ and the $\pi$ electrons in $\mathrm{C}_{2} \mathrm{H}_{2}$. From a binding energy perspective, there is not much selectivity between site 1 and site 2 in MFM-300- $\mathrm{V}^{(\mathrm{IV})}$. We again attribute the difference between MFM-300 and MIL-47 to the local steric effects near the vanadium atoms, as we discussed at the end of "Binding with $\mathrm{C}_{2} \mathrm{H}_{4}$ ” section.

\section{Implications on hydrocarbon separation}

Experimentally, the separation of a mixture of two gases is characterized by the ideal adsorbed solution theory (IAST) selectivities as a function of total gas pressure, which are deduced from adsorption isotherms of the individual components. To simulate IAST selectivities, one would typically need to carry out Grand Canonical Monte Carlo simulations $[73,74]$, which are beyond the scope of this work. Here, we attempt to infer qualitative trends on the separation of small hydrocarbons from our static calculations of binding energies. Admittedly, our analysis neglects the pressure and entropic effects. However, we believe that our calculations capture one of the most important factors, i.e., the binding preference between MOFs and hydrocarbons, which is central to the concept of "adsorptive separation." Furthermore, our calculations provide structure-property relationships for the two families of MOFs considered.

Reference [61] experimentally studied the IAST selectivities for the following equimolar mixtures: $\mathrm{C}_{2} \mathrm{H}_{6} / \mathrm{CH}_{4}, \mathrm{C}_{2} \mathrm{H}_{4}$ / $\mathrm{CH}_{4}$, and $\mathrm{C}_{2} \mathrm{H}_{2} / \mathrm{CH}_{4}$. It showed that MFM-300-V $\mathrm{V}^{(\mathrm{III})}$ features higher selectivity than MFM-300- $\mathrm{V}^{(\mathrm{IV})}$. For the difference in selectivities between the two MOFs, $\mathrm{C}_{2} \mathrm{H}_{2} / \mathrm{CH}_{4}$ is the largest, 
followed by $\mathrm{C}_{2} \mathrm{H}_{4} / \mathrm{CH}_{4}$, and the $\mathrm{C}_{2} \mathrm{H}_{6} / \mathrm{CH}_{4}$ selectivity values are almost identical for the two MOFs. Our binding energy results as listed in Table 2 correctly explain this trend: comparing MFM-300- $\mathrm{V}^{(\mathrm{III})}$ and MFM-300- $\mathrm{V}^{(\mathrm{IV})}$, the binding energies differ most in $\mathrm{C}_{2} \mathrm{H}_{2}$ (at site 1), then in $\mathrm{C}_{2} \mathrm{H}_{4}$ (at site 1), and the performances for the saturated hydrocarbons are almost identical. The preference in binding with unsaturated hydrocarbons in the MFM-300- $\mathrm{V}^{(\mathrm{III})}$, although very weak based on the binding energies, originates from the bridging - $\mathrm{OH}$ group, as we discuss above. Additionally, Ref. [61] showed that the actual IAST selectivity values are the highest for $\mathrm{C}_{2} \mathrm{H}_{2} / \mathrm{CH}_{4}$, with $\mathrm{C}_{2} \mathrm{H}_{6} / \mathrm{CH}_{4}$ slightly lower, and the lowest for $\mathrm{C}_{2} \mathrm{H}_{4} / \mathrm{CH}_{4}$, for both MFM-300- $\mathrm{V}^{(\mathrm{III})}$ and MFM-300- $\mathrm{V}^{(\mathrm{IV})}$. We note that our binding energy results do not reproduce this experimental trend. Rather, the binding energy ratio is the largest for $\mathrm{C}_{2} \mathrm{H}_{6}$ / $\mathrm{CH}_{4}$ and the smallest for $\mathrm{C}_{2} \mathrm{H}_{2} / \mathrm{CH}_{4}$, where the trend follows the molecular weight, reflecting the fact that the major binding mechanism is dispersion. One would need to consider the pressure and entropic effects in order to quantitatively reproduce the IAST selectivity values in experiment. For the same reason, our DFT binding energy results are consistently larger than the experimentally deduced isosteric heat of adsorption as reported in Ref. [61]. Nevertheless, our computed binding energies do reflect the qualitative trends in binding and separation, as discussed above.

To the best of our knowledge, the MIL-47 family has not been studied for similar small hydrocarbon separation experiments. Based on our findings, we predict that MIL-47-V(III) and MIL-47-V (IV) could also be used for hydrocarbon separation, similar to the MFM300 family. Furthermore, comparing the $\mathrm{V}^{(\mathrm{III})}$ and $\mathrm{V}^{(\mathrm{IV})}$ MOF in the MIL-47 family, their difference in binding energies with unsaturated hydrocarbons is larger than those in the MFM-300 family. Moreover, the two unsaturated hydrocarbons, $\mathrm{C}_{2} \mathrm{H}_{4}$ and $\mathrm{C}_{2} \mathrm{H}_{2}$, give rise to larger binding energies with the $\mathrm{V}^{(\mathrm{III})} \mathrm{MOF}$ than $\mathrm{C}_{2} \mathrm{H}_{6}$, in contrast to the MFM-300 family. The larger binding energy is due to the strong binding preference between $\pi$ electrons in the hydrocarbon and the bridging $-\mathrm{OH}$ in the MIL-47- $\mathrm{V}^{(\mathrm{III})}$. Such results indicate that the difference in IAST selectivities between the $\mathrm{V}^{(\mathrm{III})}$ and $\mathrm{V}^{(\mathrm{IV})}$ MOFs in the MIL-47 family might be greater than what has been experimentally observed for the MFM-300 family in Ref. [61], and the actual values of the selectivities might be larger than the corresponding MFM-300 values, too. We emphasize again that these differences stem from the structural difference between the MIL-47 and MFM-300, where the former has less steric hindrance near the bridging $-\mathrm{OH}$ group or $-\mathrm{O}$ atom such that the binding distance is shorter than that in the MFM-300 and the binding is more directional.

\section{Conclusion}

In this work, we systematically studied the binding of four small hydrocarbons- $\mathrm{CH}_{4}, \mathrm{C}_{2} \mathrm{H}_{6}, \mathrm{C}_{2} \mathrm{H}_{4}$, and $\mathrm{C}_{2} \mathrm{H}_{2}$-with two families of vanadium-based MOFs without open metal sites, namely the MFM-300 and the MIL-47 families. For each family of MOFs, we considered a structure featuring $\mathrm{V}^{(\mathrm{III})}$ and its oxidized isostructural counterpart that contains $\mathrm{V}^{(\mathrm{IV})}$. For each MOF-hydrocarbon pair, we considered two binding sites, one near the bridging - $\mathrm{OH}$ or -O group that connects two neighboring vanadium atoms, and another one located close to the linker. We carried out first-principles density functional calculations using the vdW-DF-cx functional, and demonstrated a preference in binding with unsaturated hydrocarbons at the site 1 of the $\mathrm{V}^{(\mathrm{III})}$ MOFs in both families. The preference is much stronger in the MIL-47 family than in the MFM-300 family, and we have attributed this difference to the dissimilarity of the linker in these two families. We conclude that although these MOFs do not possess open metal sites that typically lead to a preference in binding with $\pi$-electron-rich guest molecules, the bridging $-\mathrm{OH}$ or $-\mathrm{O}$ group acts as a pseudo open metal site that provides the necessary binding preference and selectivity. Our results explain existing hydrocarbon separation experiments from a binding perspective. We hope that the structure-property relationship we unveiled in our work could shine light on future design of similar porous materials.

\section{Methods}

We start our geometry optimization using experimentally determined structures and atomic coordinates whenever available $[61,75]$. All calculations employ the optimized norm-conserving Vanderbilt (ONCV) pseudopotentials [76, 77] and the vdW-DFcx functional [60] as implemented in the Quantum ESPRESSO package [78], with periodic boundary conditions along all directions. We note that a functional capturing van der Waals dispersion is required to accurately describe the binding between guest molecules and the MOF, as we have explicitly checked that the Perdew-Burke-Ernzerhof (PBE) functional leads to binding energies that are one order of magnitude smaller than those calculated using vdw-DF-cx, as expected. For MFM-300, the convergence study shows that a kinetic energy cutoff of 70 Ry and the $\Gamma$-point sampling converge the total energy per atom within $5 \mathrm{meV}$. Therefore, we use a kinetic energy cutoff of $90 \mathrm{Ry}$ (to mitigate the Pulay stress) for variable-cell relaxations of these MOFs as well as the related molecule@MOF composite systems, where we fix the symmetry of the structure to be the experimentally determined tetragonal [61]. The relaxation is considered complete when all forces are below $0.05 \mathrm{eV} / \AA$ and the pressure is below $0.5 \mathrm{kbar}$ for the simulation cell. In another convergence study, we have checked that a 120 Ry kinetic energy cutoff and 
a force criterion of $0.02 \mathrm{eV} / \AA ̊$ lead to the same binding energy (within $0.1 \mathrm{~kJ} / \mathrm{mol}$ ) as the parameters used in this work.

For the MIL-47 family, we use the same kinetic energy cutoff as above and a $\mathbf{k}$-mesh of $1 \times 1 \times 2$ for their variable-cell relaxations, where we fix the symmetry of the structure to be orthorhombic, which is the experimentally determined symmetry for MIL-47-V(IV) $[55,79]$. For MIL-47-V(III), the structure can be either monoclinic [55] or orthorhombic [56] depending on the preparation of the sample. We consider the orthorhombic phase here to facilitate a direct comparison computationally. Additionally, there is one complication regarding the relaxations of the molecule@MIL-47 systems: Ref. [80] and others showed that the "wine-rack" type of MOFs could "breathe" (a significant change in lattice parameters) when guest molecules are adsorbed within the pores. However, Refs. [81, 82] reported the rigidity of MIL-47 upon adsorption of small hydrocarbons under typical gas pressures, where its lattice parameters are nearly unchanged. Here, we follow these works and fix the lattice parameters in all molecule@MIL-47 systems as those of the corresponding MIL47 [either $\mathrm{V}^{(\mathrm{III})}$ or ${ }^{(\mathrm{IV})}$ ], and relax all atomic coordinates.

Binding energies are calculated as following: $B . E .=E(\mathrm{MOF})+n E($ molecule $)-E($ molecule@MOF $)$, where $n$ is the number of molecules adsorbed in the specific MOF. $E$ (molecule@MOF) is the total energy of the fully relaxed composite system where multiple guest molecules are adsorbed within the pores of the MOF (variable-cell relaxations for the MFM-300 family and fixed-cell relaxations for the MIL-47 family); $E(\mathrm{MOF})$ is the total energy of the fully relaxed MOF structure (variable-cell relaxation for each one); $E$ (molecule) is the total energy of one fully relaxed hydrocarbon molecule placed in a $20 \AA \times 20 \AA \times 20 \AA$ simulation box, which we calculate using a kinetic energy cutoff that is consistent with the corresponding MOF and molecule@MOF systems.

Lastly, we comment that all our conclusions above are built upon binding energies calculated using the vdW-DF-cx functional. Materials featuring localized $d$-electrons are known to be problematic for standard local and semi-local functionals. To justify that our choice of the functional is indeed suitable for this class of material, we have computed binding energies for $\mathrm{C}_{2} \mathrm{H}_{2}$ @MFM-300-V $\mathrm{V}^{(\mathrm{III})}$ and $\mathrm{C}_{2} \mathrm{H}_{2} @ M F M-300-\mathrm{V}^{(\mathrm{IV})}$ at both binding sites using vdW-DF-cx0 [83], the hybrid version of vdW-DFcx. The binding energies vary within $5 \%-10 \%$, with the trend unchanged. Such results indicate that our vdW-DF-cx results are reliable as far as the trends of binding energies are concerned.

\section{Acknowledgments}

We thank Sihai Yang for fruitful and inspiring discussions. This work was supported by the American Chemical Society Petroleum Research Fund (Award No. 61117-DNI10), and
Wayne State University start-up funds. This research used computational resources at the Center for Functional Nanomaterials, which is a U.S. Department of Energy Office of Science Facility, at Brookhaven National Laboratory under Contract No. DE-SC0012704. Additional computational resources were provided by the National Energy Research Scientific Computing Center (NERSC), a U.S. Department of Energy Office of Science User Facility operated under Contract No. DE-AC02-05CH11231.

\section{Data availability}

The datasets generated and/or analyzed during the current study are available from the corresponding author on reasonable request.

\section{Declarations}

Conflict of interest On behalf of all authors, the corresponding author states that there is no conflict of interest.

\section{Supplementary Information}

The online version contains supplementary material available at https://doi.org/10.1557/s43578-021-00356-6.

\section{Open Access}

This article is licensed under a Creative Commons Attribution 4.0 International License, which permits use, sharing, adaptation, distribution and reproduction in any medium or format, as long as you give appropriate credit to the original author(s) and the source, provide a link to the Creative Commons licence, and indicate if changes were made. The images or other third party material in this article are included in the article's Creative Commons licence, unless indicated otherwise in a credit line to the material. If material is not included in the article's Creative Commons licence and your intended use is not permitted by statutory regulation or exceeds the permitted use, you will need to obtain permission directly from the copyright holder. To view a copy of this licence, visit http://creativecommons.org/ licenses/by/4.0/.

\section{References}

1. D.S. Sholl, R.P. Lively, Seven chemical separations to change the world. Nature 532, 435 (2016)

2. Y. Ren, X. Liang, H. Dou, C. Ye, Z. Guo, J. Wang, Y. Pan, H. Wu, M.D. Guiver, Z. Jiang, Membrane-based olefin/paraffin separations. Adv. Sci. 7, 2001398 (2020)

3. N. Rangnekar, N. Mittal, B. Elyassi, J. Caro, M. Tsapatsis, Zeolite membranes: A review and comparison with MOFs. Chem. Soc. Rev. 44, 7128 (2015) 
4. S.A. Al-Muhtaseb, Role of catalyst type in the selective separation of olefinic and paraffinic hydrocarbons using xerogelbased adsorbents. Carbon 46, 1003 (2008)

5. J. Vermesse, D. Vidal, P. Malbrunot, Gas adsorption on zeolites at high pressure. Langmuir 12, 4190 (1996)

6. J. Liang, Z. Liang, R. Zou, Y. Zhao, Heterogeneous catalysis in zeolites, mesoporous silica, and metal-organic frameworks. Adv. Mater. 29, 1701139 (2017)

7. M.A. Carreon, Molecular sieve membranes for $\mathrm{N}_{2} / \mathrm{CH}_{4}$ separation. J. Mater. Res. 33, 32 (2018)

8. Q. Zhang, J. Yu, A. Corma, Applications of zeolites to C1 chemistry: Recent advances, challenges, and opportunities. Adv. Mater. 32, 2002927 (2020)

9. J.R. Long, O.M. Yaghi, The pervasive chemistry of metalorganic frameworks. Chem. Soc. Rev. 38, 1213 (2009)

10. H.C. Zhou, J.R. Long, O.M. Yaghi, Introduction to metalorganic frameworks. Chem. Rev. 112, 673 (2012)

11. J.L. Mancuso, A.M. Mroz, K.N. Le, C.H. Hendon, Electronic structure modeling of metal-organic frameworks. Chem. Rev. 120, 8641 (2020)

12. K. Munusamy, G. Sethia, D.V. Patil, P.B.S. Rallapalli, R.S. Somani, H.C. Bajaj, Sorption of carbon dioxide, methane, nitrogen and carbon monoxide on MIL-101(Cr): Volumetric measurements and dynamic adsorption studies. Chem. Eng J. 195, 359 (2012)

13. W. Morris, B. Leung, H. Furukawa, O.K. Yaghi, N. He, H. Hayashi, Y. Houndonougbo, M. Asta, B.B. Laird, O.M. Yaghi, A combined experimental-computational investigation of carbon dioxide capture in a series of isoreticular zeolitic imidazolate frameworks. J. Am. Chem. Soc. 132, 11006 (2010)

14. C. Song, Y. Ling, L. Jin, M. Zhang, D.L. Chen, Y. He, $\mathrm{CO}_{2}$ adsorption of three isostructural metal-organic frameworks depending on the incorporated highly polarized heterocyclic moieties. Dalton Trans. 45, 190 (2016)

15. L. Ge, R. Lin, Z. Zhu, H. Wang, A nitrogen-doped electrocatalyst from metal-organic framework-carbon nanotube composite. J. Mater. Res. 33, 538 (2018)

16. X.-J. Yin, L.-G. Zhu, High-efficiency photocatalytic performance and mechanism of silver-based metal-organic framework. J. Mater. Res. 34, 991 (2019)

17. O.V. Kharissova, B.I. Kharisov, I.E. Ulyand, T.H. García, Catalysis using metal-organic framework-derived nanocarbons: Recent trends. J. Mater. Res. 35, 2190 (2020)

18. L. Zhang, H. Li, H. Xie, T. Chen, C. Yang, J. Wang, MOF-driven ultra-small hollow Co9S8 nanoparticles embedded in porous carbon for lithium-ion batteries. J. Mater. Res. 33, 1496 (2018)

19. H. Li, L. Chi, C. Yang, L. Zhang, F. Yue, J. Wang, MOF derived porous Co@C hexagonal-shaped prisms with high catalytic performance. J. Mater. Res. 31, 3069 (2016)

20. M.P. Suh, H.J. Park, T.K. Prasad, D.W. Lim, Hydrogen storage in metal-organic frameworks. Chem. Rev. 112, 782 (2012)
21. X. Lin, J. Jia, P. Hubberstey, M. Schröder, N.R. Champness, Hydrogen storage in metal-organic frameworks. CrystEngComm 9, $438(2007)$

22. J.R. Li, R.J. Kuppler, H.C. Zhou, Selective gas adsorption and separation in metal-organic frameworks. Chem. Soc. Rev. 38, 1477 (2009)

23. Z. Bao, G. Chang, H. Xing, R. Krishna, Q. Ren, B. Chen, Potential of microporous metal-organic frameworks for separation of hydrocarbon mixtures. Energy Environ. Sci. 9, 3612 (2016)

24. Z. Bao, S. Alnemrat, L. Yu, I. Vasiliev, Q. Ren, X. Lu, S. Deng, Adsorption of ethane, ethylene, propane, and propylene on a magnesium-based metal-organic framework. Langmuir 27, 13554 (2011)

25. F.S. Tang, R.B. Lin, R.G. Lin, J.C.G. Zhao, B. Chen, Separation of $\mathrm{C}_{2}$ hydrocarbons from methane in a microporous metal-organic framework. J. Solid State Chem. 258, 346 (2018)

26. R.B. Lin, S. Xiang, W. Zhou, B. Chen, Microporous metalorganic framework materials for gas separation. Chemistry 6 , 337 (2020)

27. X. Zhao, Y. Wang, D.S. Li, X. Bu, P. Feng, Metal-organic frameworks for separation. Adv. Mater. 30, 1705189 (2018)

28. O.V. Kharissova, B.I. Kharisov, L.T. González, Recent trends on density functional theory-assisted calculations of structures and properties of metal-organic frameworks and metal-organic frameworks-derived nanocarbons. J. Mater. Res. 35, 1424 (2020)

29. C. Wang, D. Liu, W. Lin, Metal-organic frameworks as a tunable platform for designing functional molecular materials. J. Am. Chem. Soc. 135, 13222 (2013)

30. Z. Chen, H. Jiang, M. Li, M. O'Keeffe, M. Eddaoudi, Reticular chemistry 3.2: Typical minimal edge-transitive derived and related nets for the design and synthesis of metal-organic frameworks. Chem. Rev. 120, 8039 (2020)

31. H. Jiang, J. Jia, A. Shkurenko, Z. Chen, K. Adil, Y. Belmabkhout, L.J. Weselinski, A.H. Assen, D.X. Xue, M. O'Keeffe, M. Eddaoudi, Enriching the reticular chemistry repertoire: Merged nets approach for the rational design of intricate mixed-linker metalorganic framework platforms. J. Am. Chem. Soc. 140, 8858 (2018)

32. S. Lirio, Y.H. Shih, S.Y. Hsiao, J.H. Chen, H.T. Chen, W.L. Liu, C.H. Lin, H.Y. Huang, Monitoring the effect of different metal centers in metal-organic frameworks and their adsorption of aromatic molecules using experimental and simulation studies. Chem. Eur. J. 24, 14044 (2018)

33. H. Wang, Y. Liu, J. Li, Designer metal-organic frameworks for size-exclusion-based hydrocarbon separations: Progress and challenges. Adv. Mater. 32, 2002603 (2020)

34. L. Yang, S. Qian, X. Wang, X. Cui, B. Chen, H. Xing, Energyefficient separation alternatives: Metal-organic frameworks and membranes for hydrocarbon separation. Chem. Soc. Rev. 49, 5359 (2020) 
35. T. Lan, L. Li, Y. Chen, X. Wang, J. Yang, J. Li, Opportunities and critical factors of porous metal-organic frameworks for industrial light olefins separation. Mater. Chem. Front. 4, 1954 (2020)

36. Ü. Kökçam-Demir, A. Goldman, L. Esrafili, M. Gharib, A. Morsali, O. Weingart, C. Janiak, Coordinatively unsaturated metal sites (open metal sites) in metal-organic frameworks: Design and applications. Chem. Soc. Rev. 49, 2751 (2020)

37. X.J. Hou, P. He, H. Li, X. Wang, Understanding the adsorption mechanism of $\mathrm{C}_{2} \mathrm{H}_{2}, \mathrm{CO}_{2}$, and $\mathrm{CH}_{4}$ in isostructural metalorganic frameworks with coordinatively unsaturated metal sites. J. Phys. Chem. C 117, 2824 (2013)

38. H. Demir, S.J. Stoneburner, W. Jeong, D. Ray, X. Zhang, O.K. Farha, C.J. Cramer, J.I. Siepmann, L. Gagliardi, Metal-organic frameworks with metal-catecholates for $\mathrm{O}_{2} / \mathrm{N}_{2}$ separation. J. Phys. Chem. C 123, 12935 (2019)

39. M.V. Parkes, D.F. SavaGallis, J.A. Greathouse, T.M. Nenoff, Effect of metal in $\mathrm{M}_{3}$ (btc) $)_{2}$ and $\mathrm{M}_{2}$ (dobdc) MOFs for $\mathrm{O}_{2} / \mathrm{N}_{2}$ separations: A combined density functional theory and experimental study. J. Phys. Chem. C 119, 6556 (2015)

40. Y. Wu, H. Chen, J. Xiao, D. Liu, Z. Liu, Y. Qian, H. Xi, Adsorptive separation of methanol-acetone on isostructural series of metalorganic frameworks M-BTC $(\mathrm{M}=\mathrm{Ti}, \mathrm{Fe}, \mathrm{Cu} \mathrm{Co}, \mathrm{Ru}, \mathrm{Mo}): \mathrm{A}$ computational study of adsorption mechanisms and metal-substitution impacts. ACS Appl. Mater. Interfaces 7, 26930 (2015)

41. K. Tan, S. Zuluaga, H. Wang, P. Canepa, K. Soliman, J. Cure, J. $\mathrm{Li}, \mathrm{T}$. Thonhauser, Y.J. Chabal, Interaction of acid gases $\mathrm{SO}_{2}$ and $\mathrm{NO}_{2}$ with coordinatively unsaturated metal organic frameworks: M-MOF-74 (M = Zn, Mg, Ni, Co). Chem. Mater. 29, 4227 (2017)

42. Z.R. Herm, E.D. Bloch, J.R. Long, Hydrocarbon separations in metal-organic frameworks. Chem. Mater. 26, 323 (2014)

43. H. Kim, J. Park, Y. Jung, The binding nature of light hydrocarbons on Fe/MOF-74 for gas separation. Phys. Chem. Chem. Phys. 15, 19644 (2013)

44. P. Verma, X. Xu, D.G. Truhlar, Adsorption on Fe-MOF-74 for $\mathrm{C}_{1}$ $-\mathrm{C}_{3}$ hydrocarbon separation. J. Phys. Chem. C 117, 12648 (2013)

45. B.R. Barnett, M.I. Gonzalez, J.R. Long, Recent progress towards light hydrocarbon separations using metal-organic frameworks. Trends Chem. 1, 159 (2019)

46. W. You, T. Sen, Y. Kawajiri, M.J. Realff, D.S. Sholl, Using site heterogeneity in metal-organic frameworks with bimetallic open metal sites for olefin/paraffin separations. ACS Appl. Nano Mater. 3, 5291 (2020)

47. K. Sumida, D.L. Rogow, J.A. Mason, T.M. McDonald, E.D. Bloch, Z.R. Herm, T.-H. Bae, J.R. Long, Carbon dioxide capture in metal-organic frameworks. Chem. Rev. 112, 724 (2012)

48. S. Yang, J. Sun, A.J. Ramirez-Cuesta, S.K. Callear, W.I. David, D.P. Anderson, R. Newby, A.J. Blake, J.E. Parker, C.C. Tang, M. Schroder, Selectivity and direct visualization of carbon dioxide and sulfur dioxide in a decorated porous host. Nat. Chem. 4, 887 (2012)
49. S. Yang, A.J. Ramirez-Cuesta, R. Newby, V. Garcia-Sakai, P. Manuel, S.K. Callear, S.I. Campbell, C.C. Tang, M. Schröder, Supramolecular binding and separation of hydrocarbons within a functionalized porous metal-organic framework. Nat. Chem. 7, 121 (2015)

50. C.P. Krap, R. Newby, A. Dhakshinamoorthy, H. García, I. Cebula, T.L. Easun, M. Savage, J.E. Eyley, S. Gao, A.J. Blake, W. Lewis, P.H. Beton, M.R. Warren, D.R. Allan, M.D. Frogley, C.C. Tang, G. Cinque, S. Yang, M. Schroder, Enhancement of $\mathrm{CO}_{2}$ adsorption and catalytic properties by Fe-doping of $\left[\mathrm{Ga}_{2}(\mathrm{OH})_{2}(\mathrm{~L})\right]$ $\left(\mathrm{H}_{4} \mathrm{~L}=\right.$ biphenyl-3,3',5,5'-tetracarboxylic acid), MFM-300 $\left(\mathrm{Ga}_{2}\right)$. Inorg. Chem. 55, 1076 (2016)

51. M. Savage, I. Da Silva, M. Johnson, J.H. Carter, R. Newby, M. Suyetin, E. Besley, P. Manuel, S. Rudić, A.N. Fitch, C. Murray, W.I. David, S. Yang, M. Schröder, Observation of binding and rotation of methane and hydrogen within a functional metalorganic framework. J. Am. Chem. Soc. 138, 9119 (2016)

52. Z. Lu, H.G. Godfrey, I. Da Silva, Y. Cheng, M. Savage, F. Tuna, E.J. McInnes, S.J. Teat, K.J. Gagnon, M.D. Frogley, P. Manuel, S. Rudic, A.J. Ramirez-Cuesta, T.L. Easun, S. Yang, M. Schroder, Modulating supramolecular binding of carbon dioxide in a redox-active porous metal-organic framework. Nat. Commun. 8, 14212 (2017)

53. X. Han, H.G. Godfrey, L. Briggs, A.J. Davies, Y. Cheng, L.L. Daemen, A.M. Sheveleva, F. Tuna, E.J. McInnes, J. Sun, C. Drathen, M.W. George, A.J. Ramirez-Cuesta, K.M. Thomas, S. Yang, M. Schroder, Reversible adsorption of nitrogen dioxide within a robust porous metal-organic framework. Nat. Mater. 17, 691 (2018)

54. X. Zhang, I. Da Silva, R. Fazzi, A.M. Sheveleva, X. Han, B.F. Spencer, S.A. Sapchenko, F. Tuna, E.J. McInnes, M. Li, S. Yang, M. Schroder, Iodine adsorption in a redox-active metal-organic framework: Electrical conductivity induced by host-guest charge-transfer. Inorg. Chem. 58, 14145 (2019)

55. H. Leclerc, T. Devic, S. Devautour-Vinot, P. Bazin, N. Audebrand, G. Ferey, M. Daturi, A. Vimont, G. Clet, Influence of the oxidation state of the metal center on the flexibility and adsorption properties of a porous metal organic framework: MIL47(V). J. Phys. Chem. C 115, 19828 (2011)

56. S. Biswas, D.E.P. Vanpoucke, T. Verstraelen, M. Vandichel, S. Couck, K. Leus, Y.-Y. Liu, M. Waroquier, V. Van Speybroeck, J.F.M. Denayer, P. Van Der Voort, New functionalized metalorganic frameworks MIL-47-X $\left(\mathrm{X}=-\mathrm{Cl},-\mathrm{Br},-\mathrm{CH}_{3},-\mathrm{CF}_{3}\right.$, $\left.-\mathrm{OH},-\mathrm{OCH}_{3}\right)$ : Synthesis, characterization, and $\mathrm{CO}_{2}$ adsorption properties. J. Phys. Chem. C 117, 22784 (2013)

57. K. Momma, F. Izumi, VESTA: A three-dimensional visualization system for electronic and structural analysis. J. Appl. Crystallogr. 41, 653 (2008)

58. P. Hohenberg, W. Kohn, Inhomogeneous electron gas. Phys. Rev. 136, 864 (1964) 
59. W. Kohn, L.J. Sham, Self-consistent equations including exchange and correlation effects. Phys. Rev. 140, A1133 (1965)

60. K. Berland, P. Hyldgaard, Exchange functional that tests the robustness of the plasmon description of the van der Waals density functional. Phys. Rev. B 89, 035412 (2014)

61. Z. Lu, H.G. Godfrey, I. Da Silva, Y. Cheng, M. Savage, P. Manuel, S. Rudic, A.J. Ramirez-Cuesta, S. Yang, M. Schroder, Direct observation of supramolecular binding of light hydrocarbons in vanadium (III) and (IV) metal-organic framework materials. Chem. Sci. 9, 3401 (2018)

62. A.U. Ortiz, A. Boutin, A.H. Fuchs, F.-X. Coudert, Metalorganic frameworks with wine-rack motif: What determines their flexibility and elastic properties? J. Chem. Phys. 138, 174703 (2013)

63. K. Barthelet, J. Marrot, D. Riou, G. Férey, A breathing hybrid organic-inorganic solid with very large pores and high magnetic characteristics. Angew. Chem. 41, 281 (2002)

64. R. Babarao, Z. Hu, J. Jiang, S. Chempath, S.I. Sandler, Storage and separation of $\mathrm{CO}_{2}$ and $\mathrm{CH}_{4}$ in silicalite, $\mathrm{C}_{168}$ schwarzite, and IRMOF-1: A comparative study from Monte Carlo simulation. Langmuir 23, 659 (2007)

65. X. Peng, X. Cheng, D. Cao, Computer simulations for the adsorption and separation of $\mathrm{CO}_{2} / \mathrm{CH}_{4} / \mathrm{H}_{2} / \mathrm{N}_{2}$ gases by UMCM-1 and UMCM-2 metal-organic frameworks. J. Mater. Chem. 21, 11259 (2011)

66. G. Alonso, D. Bahamon, F. Keshavarz, X. Giménez, P. Gamallo, R. Sayós, Density functional theory-based adsorption isotherms for pure and flue gas mixtures on Mg-MOF-74. Application in $\mathrm{CO}_{2}$ capture swing adsorption processes. J. Phys. Chem. C 122, 3945 (2018)

67. K. Peterson, W. Klemperer, Water-hydrocarbon interactions: Structure and internal rotation of the water-ethylene complex. J. Chem. Phys. 85, 725 (1986)

68. I.N. Senchenya, V.B. Kazansky, Quantum chemical studies of ethylene interaction with zeolite OH-groups. Catal. Lett. 8, 317 (1991)

69. Q.-S. Du, Q.-Y. Wang, L.-Q. Du, D. Chen, R.-B. Huang, Theoretical study on the polar hydrogen- $\pi(\mathrm{Hp}-\pi)$ interactions between protein side chains. Chem. Cent. J. 7, 92 (2013)

70. S. Horowitz, R.C. Trievel, Carbon-oxygen hydrogen bonding in biological structure and function. J. Biol. Chem. 287, 41576 (2012)

71. T. Steiner, Effect of acceptor strength on $\mathrm{C}-\mathrm{H} \cdots \mathrm{O}$ hydrogen bond lengths as revealed by and quantified from crystallographic data. J. Chem. Soc. Chem. Commun. 20, 2341 (1994)

72. T. Steiner, $\mathrm{C}-\mathrm{H} \cdots \mathrm{O}$ hydrogen bonding in crystals. Crystallogr. Rev. 6, 1 (1996)

73. T.V. Heest, S.L. Teich-McGoldrick, J.A. Greathouse, M.D. Allendorf, D.S. Sholl, Identification of metal-organic framework materials for adsorption separation of rare gases: Applicability of ideal adsorbed solution theory (IAST) and effects of inaccessible framework regions. J. Phys. Chem. C 116, 13183 (2012)
74. E. Sauer, J. Gross, Prediction of adsorption isotherms and selectivities: Comparison between classical density functional theory based on the perturbed-chain statistical associating fluid theory equation of state and ideal adsorbed solution theory. Langmuir 35, 11690 (2019)

75. D.E.P. Vanpoucke, J.W. Jaeken, S.D. Baerdemacker, K. Lejaeghere, V.V. Speybroeck, Quasi-1D physics in metal-organic frameworks: MIL-47(V) from first principles. Beilstein J. Nanotechnol. 5, $1738(2014)$

76. D.R. Hamann, Optimized norm-conserving Vanderbilt pseudopotentials. Phys. Rev. B 88, 085117 (2013)

77. M. Schlipf, F. Gygi, Optimization algorithm for the generation of ONCV pseudopotentials. Comput. Phys. Commun. 196, 36 (2015)

78. P. Giannozzi, O. Andreussi, T. Brumme, O. Bunau, M. B. Nardelli, M. Calandra, R. Car, C. Cavazzoni, D. Ceresoli, M. Cococcioni, N. Colonna, I. Carnimeo, A. D. Corso, S. de Gironcoli, P. Delugas, R. A. DiStasio Jr, A. Ferretti, A. Floris, G. Fratesi, G. Fugallo, R. Gebauer, U. Gerstmann, F. Giustino, T. Gorni, J. Jia, M. Kawamura, H.-Y. Ko, A. Kokalj, E. Küçükbenli, M. Lazzeri, M. Marsili, N. Marzari, F. Mauri, N. L. Nguyen, H.-V. Nguyen, A. O. de-la Roza, L. Paulatto, S. Poncé, D. Rocca, R. Sabatini, B. Santra, M. Schlipf, A. P. Seitsonen, A. Smogunov, I. Timrov, T. Thonhauser, P. Umari, N. Vast, X. Wu, S. Baroni, Advanced capabilities for materials modelling with Quantum ESPRESSO, J. Phys. Condens. Matter 29, 465901 (2017)

79. P. Van Der Voort, K. Leus, Y.-Y. Liu, M. Vandichel, V. Van Speybroeck, M. Waroquier, S. Biswas, Vanadium metal-organic frameworks: Structures and applications. New J. Chem. 38, 1853 (2014)

80. J.P. Zhang, H.L. Zhou, D.D. Zhou, P.Q. Liao, X.M. Chen, Controlling flexibility of metal-organic frameworks. Natl. Sci. Rev. 5, 907 (2018)

81. I. Déroche, S. Rives, T. Trung, Q. Yang, A. Ghouf, N.A. Ramsahye, P. Trens, F. Fajula, T. Devic, C. Serre, G. Férey, H. Jobic, G. Maurin, Exploration of the long-chain $\mathrm{N}$-alkanes adsorption and diffusion in the MOF-Type MIL-47 (V) material by combining experimental and molecular simulation tools. J. Phys. Chem. C 115, 13868 (2011)

82. N. Rosenbach Jr., A. Ghoufi, I. Déroche, P.L. Llewellyn, T. Devic, S. Bourrelly, C. Serre, G. Férey, G. Maurin, Adsorption of light hydrocarbons in the flexible MIL-53(Cr) and rigid MIL-47(V) metal-organic frameworks: A combination of molecular simulations and microcalorimetry/gravimetry measurements. Phys. Chem. Chem. Phys. 12, 6428 (2010)

83. K. Berland, Y. Jiao, J.-H. Lee, T. Rangel, J.B. Neaton, P. Hyldgaard, Assessment of two hybrid van der Waals density functionals for covalent and non-covalent binding of molecules. J. Chem. Phys. 146, 234106 (2017) 